\title{
Tyrosine-Protein Kinase BTK
}

National Cancer Institute

\section{Source}

National Cancer Institute. Tyrosine-Protein Kinase BTK. NCI Thesaurus. Code C75017.

Tyrosine-protein kinase BTK (659 aa, 76 kDa) is encoded by the human BTK gene. This protein is involved in both B-cell development and signal transduction. 